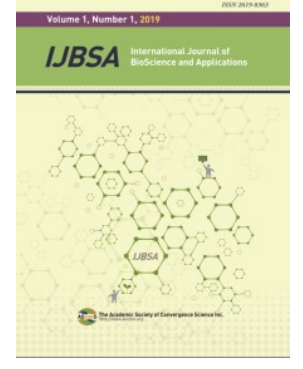

International Journal of

BioScience and Applications

\title{
Review of the Long-Term Care Insurance System for the Elderly and Visiting Nursing
}

\author{
Ja-Ok Kim¹, Hack-Sun Kim¹, Yeo-jin Kim¹, Seung-Ju Kang ${ }^{2}$ and Suhyun Kim ${ }^{3 *}$ \\ ${ }^{1}$ Department of Nursing, Wonkwang Health Science University, Iksan, Republic of Korea \\ ${ }^{2}$ Department of Nursing, Chunnam Techno University, Gokseong-gun, Jeollanam-do, Republic of Korea \\ ${ }^{3}$ Department of Nursing, Nambu University, Gwangju, Public of Korea
}

\begin{abstract}
Background/Objectives: This study was attempted to organize the long-term care insurance system for the elderly and visiting nursing. Methods/Statistical analysis: This is a review of the long-term care insurance system for the elderly and visiting nursing. Findings: The Ministry of Health and Welfare is in charge of overall policy and system improvement of long-term care insurance for the elderly. In accordance with Article 48 of the Long-Term Care Insurance for the Elderly Act, the insurer, the National Health Insurance Corporation, performs the roles of collection of premiums, accreditation investigations and ratings, payment of benefits for service provision, and institutional evaluation and support for use. Visiting nursing is performed by nurses and nursing assistants who have completed the nursing assistant training course and obtained certificates. Visiting nursing assistant nurse education is provided by the Lifelong Education Center of the university. Looking at the curriculum of the Lifelong Education Center, it is necessary to strengthen the human rights and safety-related aspects of the elderly in an epidemic situation such as COVID-19 to be more realistic. Improvements/Applications: It is intended to be applied as basic data for research on the long-term care insurance system for the elderly and visiting nursing.
\end{abstract}

\section{Index Terms}

Review, Long-term care insurance system for the elderly, Visiting nursing, National health insurance system.

\footnotetext{
Corresponding author : Suhyun Kim

ksh136112@nambu.ac.kr

- Manuscript received October 15, 2021.

- Revised November 10, 2021 ; Accepted December 1, 2021.

- Date of publication December 30, 2021

(c) The Academic Society of Convergence Science Inc.

2619-8363 @ 2021 IJBSA. Personal use is permitted, but republication/redistribution requires IJBSA permission.
} 


\section{INTRODUCTION}

Long-term care insurance for the elderly provides services such as physical activity and housework support to the elderly who have difficulty in daily living alone due to old age or geriatric diseases. It is a social insurance system that helps to improve the quality of life of the people by promoting health and living stability in old age and reducing the burden on their families. Due to the aging population and changes in the disease structure, the elderly population in need of nursing care has increased rapidly. Due to the increase in the duration of illness, the burden of medical care and medical expenses for the elderly increased. The low fertility rate, the phenomenon of nuclear families, and the increase in women's participation in society have made it difficult to support the elderly at home. Against this background, the government introduced the longterm care insurance system for the elderly for social responsibility. And according to previous studies, the use of medical services decreased with the introduction of the long-term care insurance system for the elderly in $2008[1,2]$. According to the results of a study targeting long-term care facilities, $30 \%$ of the elderly in the hospital needed medical services [3].

In April 2007, the government enacted the LongTerm Care Insurance Act for the Elderly. On July 1, 2008, the long-term care insurance system for the elderly was implemented. In March 2008, the first grade evaluation committee was formed. In March 2011, the 2nd grade evaluation committee was formed. In July 2013, the rating criteria were relaxed to 51points. In March 2017, the 4th grade evaluation committee was formed. On January 1, 2018, the cognitive support level was newly established. In March 2020, the 5th grade evaluation committee was formed. As the number of senior citizens with dementia increased, the long-term care insurance system introduced the dementia supplementary point system in July 2011 to reflect the characteristics of dementia. In July 2014, a special grade for dementia, grade 6, was newly established. In January 2018, the cognitive support level was newly established [4]. Those who need to confirm the diagnosis of dementia have written a doctor's opinion, which is a supplementary document that can determine the level of dementia.

For the service use procedure of the long-term care insurance system for the elderly, an application for recognition must be made through the person or his/her agent. The National Health Insurance Corporation staff conducts an accreditation investigation. The grade evaluation committee conducts grading. The results are notified to the
National Health Insurance Corporation. Recipients and long-term care institutions use services through contracts. Benefit types include home benefit, facility benefit, and family medical expenses. Home benefits include visiting care, visiting bathing, visiting nursing, day/night care, short-term care, and other home benefits. There are facilities for elderly care for more than 10 people and home facilities for senior citizens with less than 9 people. Family care expenses apply to those who live in areas that are markedly lacking in long-term care institutions such as islands and remote areas. Nursing homes for the elderly are important in solving the problems of the elderly in their old age [5]. A person recognized by the Minister of Health and Welfare that it is difficult to use long-term care benefits due to natural disasters, etc [6]. A person who needs long-term care from a family member due to physical, mental, or personality reasons. Patients with infectious diseases, psychopaths, and subjects of body transformation.

As the population aging and chronic diseases increase, long-term care insurance for the elderly can be said to show the level of welfare in Korea. This study was attempted to organize the long-term care insurance system for the elderly and visiting nursing.

\section{MATERIALS AND METHOD}

\section{A. Study Design}

This is a review study on the long-term care insurance system for the elderly and visiting nursing.

\section{B. Research Process}

$\checkmark$ Comparison between the long-term care insurance system for the elderly and the national health insurance system

1) Long-term care insurance for the elderly system

- Beneficiary: those who are recognized for long-term care

- Benefit: Support for physical and cognitive support activities

- Benefit providers: long-term care workers such as caregivers, nurses, social workers, etc.

- Benefit provider agency: Long-term care institutions (residence long-term care institutions, nursing facilities, etc.)

- Applicable law: Long-term care insurance for the elderly

- Benefit expense review: National Health Insurance Service(NHIS)

2) National health insurance system

Beneficiary: Health insurance subscribers and dependents

- Benefits: prevention, diagnosis, 
- treatment, rehabilitation and childbirth, death and health promotion for diseases and injuries

- Benefit providers: medical personnel such as doctors and nurses

- Benefit provider agency : Nursing care institutions (medical institutions, pharmacies, etc.)

- Applicable laws: National Health Insurance Act, Medical Act, Pharmacist Act, Regional Health Act, etc.

- Benefit expense review: Health Insurance Review \& Assessment Service(HIRA)

\section{RESUlt AND DiscuSSION}

\section{A. Long-term care insurance for the elderly}

If the elderly 65 years of age or older or those under the age of 65 with geriatric diseases such as dementia or cerebrovascular disease are determined to be recipients because it is difficult to carry out daily life alone for 6 months or more It is a system that can receive long-term care benefits such as support.

\section{1) Classification of long-term care}

- Long-term care Grade 1: A person who need help from others in their daily life due to mental and physical dysfunction and have a score of 96 or higher for long-term care

- Long-term care Grade 2: A person who need help from others in their daily life due to impairments in the functional state of mind and body, and who have a long-term care certification score of 75 or more but less than 96

- Long-term care Grade 3: A person who partially needs help from others in daily life due to a disorder in the functional state of mind and body, and has a long-term care approval score of 60 or more but less than 75

- Long-term care Grade 4: A person who needs help from others in daily life to some extent in his or her daily life due to a disorder in the functional state of the body

- Long-term care Grade 5: A person dementia (limited to dementia that falls under geriatric diseases under Article 2 of the Enforcement Decree of the Long-Term Care Insurance Act for the Elderly) with a long-term care recognition score of 45 or more but less than 51

- Long-term care cognitive support level: A person with dementia (limited to dementia that falls under geriatric diseases under
Article 2 of the Enforcement Decree of the Long-Term Care Insurance Act for the Elderly) and has a long-term care recognition score of less than 45

\section{B. Grade evaluation [7]}

1) Long-term care approval flow chart

- Long-term care application: accreditation application (initial), renewal application, grade change application

- Visitation survey: preparation of accreditation questionnaire, identification of special matters

- Registration of doctor's opinion: Applicants who are expected to rank 5 must submit a general opinion and supplementary documents (cognitive support level)

- Review by the rating committee: those who are recognized (grades 1-5, cognitive support grade), those who are outside the grade (welfare, prevention)

From the long-term care application to the review of the rating committee, it must be completed within 30 days. The decision on re-investigation and re-examination must be completed within 60 days.

2) Composition of the accreditation questionnaire

- 90 accreditation questionnaires: 25 needs surveys, 65 accreditation surveys (52 items reflected in the calculation of the medical care accreditation score, 13 items reflected in the rating deliberation index)

- 52 items counted in the accreditation score: 12 items for physical function, 7 items for cognition, 14 items for behavior, 9 items for nursing, 10 items for rehabilitation

- Raw score for each area: 52 items calculated in the accreditation score are calculated as 1 point for complete independence, 2 points for partial assistance, and 3 points for complete assistance by area

- 100-point conversion score for each area: Based on the original score for each area, the score is calculated according to the 100-point conversion score table

- A total of 8 tree diagrams: cleanliness, excretion, meals, functional assistance, behavior change, indirect support, nursing care, rehabilitation training

C. Types of long-term care benefits [6, 7]

1) Home benefits

- Visiting care: A caregiver (long-term care worker) visits the home of the recipient and supports physical and housekeeping activities. 
- Visit bathing: Long-term nursing homes use equipment equipped with bathing facilities to visit beneficiaries' homes and provide baths.

- Visiting Nursing: Nurses, assistant nurse, and dental hygienists visit beneficiaries' homes, etc. in accordance with the visiting nursing instructions of doctors, oriental doctors, or dentists to provide nursing care, assistance in treatment, counseling or education on recuperation, and oral hygiene.

- Day and night protection: Provides education and training for physical and cognitive activity support and maintenance and improvement of mental function by protecting recipients at a long-term care institution for a certain time during the day (including the dementia center in day and night protection)

- Short-term care: Provides education and training for physical activity support and maintenance and improvement of cardiac function by protecting beneficiaries at long-term care institutions for a certain period of time.

- Cognitive activity-type visiting nursing care: A caregiver who has completed dementiaspecialized education provides cognitive stimulation activities using cognitive training tools and performs daily life such as folding clothes, meal preparation, and personal hygiene activities with the recipient, and the remaining physical and cognitive functions provide training for the maintenance

\section{2) Other Home Benefits: Welfare Equipment}

3) Facility benefits: Elderly care facilities, senior citizens care for shared living families

\section{4) Special Cash Benefits: Family Medical Expenses}

\section{Visiting nursing}

Visiting nursing means that a nurse (assistantnurse) or a dental hygienist visits a recipient's home and provides nursing and treatment, education, counseling, and oral hygiene in accordance with the visiting nursing instruction. Among the recipients of grades 1 to 5 who use visiting care or bathing, recipients who need nursing treatment can use visiting nursing for preventive management, etc., regardless of the monthly limit, only once a month. Recipients of grades 1 to 5 dementia who received the long-term care grade for the first time can use the visiting nursing service up to 4 times (twice a month) within 60 days of receiving the grade at no cost. In this case, visiting nursing is provided by a nurse or a assistant nurse who has completed dementia education [8]. In order to use visiting nursing, you must obtain a visiting nursing instruction from a medical institution. Then, visit nursing pay will be used next [6].

\section{1) Visiting nursing center director}

Visiting nursing according to the Enforcement Decree of the Long-Term Care Insurance for the Elderly is a person who has more than 2 years of nursing experience as a nurse in accordance with Article 2 of the Medical Act.

\section{2) Visiting nursing assistant nurse}

In accordance with Article 80 of the Medical Act, a person who has 3 or more years of experience as a assistant-nurse and has completed education prescribed by the Minister of Health and Welfare.

\section{3) Lifelong Education Center Curriculum}

The total education duration is 700 hours. The theory is 360 hours. Practice is 340 hours. As for the dedicated workforce, there is one full-time professor of nursing department, one social worker with a firstlevel certificate, and one with a first-level nutritionist certificate. Lecture duration is 50 minutes, followed by a 10-minute break. The standard of evaluation score for completion of education is 70 points or more for each subject. Attendance is $80 \%$ or more for each subject.

\section{- Theory : 360 hours}

Long-term care insurance system for the elderly 15 hours, understanding of welfare for the elderly 15 hours, aging and chronic diseases 90 hours, human relationships and communication 15 hours, nutrition and diet 15 hours, medical terminology and records 15 hours, basic nursing 90 hours, physical assessment is 30 hours, safety and infection control 15 hours, family nursing 15 hours, first aid 15 hours, visiting nursing ethics 15 hours, and end-of-life care 15 hours. In principle, face-to-face lectures are provided at the university's lifelong education center, but in the case of COVID-19, temporary non-face-toface lectures were conducted [9].

\section{- Practice : 340 hours}

There are 100 hours of laboratory practice on campus, 220 hours of practice at medical institutions, and 20 hours of practice at health institutions. In the context of COVID-19, health institution practice has been replaced by medical institution practice [9].

4) Visiting Nursing Intervention

- Basic health management: Check health status

- Measurement of vital signs 
- Blood sugar and urine sugar test

- Observation of health status

- Basic Nursing: Hygiene management

- Mouth care

- Special mouth care

- Eye, ear and nose care

- Physical training: joint contracture, movement disorders

- Active range of motion exercise,

- Passive range of motion exercise,

- Pedestrian management

- Disease management: medication management, pain management, infection prevention, respiratory care, wound management, Bed sore

- Drug management

- Management of medication administration

- Pain assessment

- Hot and cold therapy

- Prevention of infection

- Bronchial tube suction

- Bronchial tube management

- Oxygen therapy

- Simple wound dressing

- Inflammatory wound dressing

- Foot care

- Prevention of bed sores

- Bedsore Nursing

Cognitive training: cognitive dysfunction

- Cognitive function evaluation

- Cognitive function enhancement

Nutrition management: Nutrition management

- Check nutritional status

- Body fluid management

- Enhance swallowing function

- Levin tube diet

- Exchange and management of nasogastric tube

- Excretion management: urination disorder, defecation disorder

- Nelaton catheterization

- Indwelling catheter insertion and management

- Urination training

- Bladder irrigation

- Enema

- Stoma care

\section{CONCLUSION}

The Ministry of Health and Welfare is in charge of overall policy and system improvement of long-term care insurance for the elderly. In accordance with Article 48 of the Long-Term Care Insurance for the
Elderly Act, the insurer, the National Health Insurance Corporation, performs the roles of collection of premiums, accreditation investigations and ratings, payment of benefits for service provision, and institutional evaluation and support for use. Visiting nursing is performed by nurses and nursing assistants who have completed the nursing assistant training course and obtained certificates. Visiting nursing assistant nurse education is provided by the Lifelong Education Center of the university. Looking at the curriculum of the Lifelong Education Center, it is necessary to strengthen the human rights and safety-related aspects of the elderly in an epidemic situation such as COVID-19 to be more realistic. Elderly people with reduced mobility are a vulnerable group in the face of infectious diseases. In the case of caregivers, the National Health Insurance Corporation composes systematic textbooks. However, each university's Lifelong Education Center is in charge of the visiting nursing assistant training course individually. For important parts, systematic development of textbooks is required centered on the national department in charge. A systematic policy should be presented for the manpower produced through the Lifelong Education Center.

The most important thing in the long-term care insurance system for the elderly is to provide quality long-term care benefit services by selecting those who need long-term care benefits. In particular, the majority of consumers of the long-term care insurance system for the elderly are the elderly. In order to meet the demand for services for the elderly, the management and formation of human support, which is a benefit provider, should be the basis [10, 11]. Long-term care insurance for the elderly is considered to be able to fulfill its social responsibilities as a gateway to lead a healthy life for the people when such consumer-oriented long-term care benefit services are reflected.

The committee activities related to the long-term care insurance system for the elderly and the lifelong education center operated the visiting nursing assistant nurse course. This review study intends to provide basic data on the long-term care insurance system for the elderly and visiting nursing. In the follow-up study, we would like to suggest quantitative and qualitative research related to longterm care insurance for the elderly and visiting nursing.

It is considered that the visiting nursing assistant nurse course taught at the Lifelong Education Center is meaningful as a social responsibility and in line with the purpose of lifelong education that provides an opportunity to study. 


\section{REFERENCES}

[1] Hyun, K., Kang, S., and Lee, S. (2014). Does long-term care insurance affect the length hospitals for the elderly in Korea?: A difference-in-difference method, BMC Health Services Research, 14, 1-7

[2] Kim, H. B., Lim, W. (2015). Long-term care insurance, informal care and medical expenditures, Journal of Public Economics, 125, 128-142.

[3] Kim, H., Jung, Y. I. and Kwon, S. (2015). Delivery of insitutional long-term care under two social insurances: Lessons form the Korean experience, Health Policey, 119(10), 1330-1337.

[4] Korea Ministry of Government Legislation. Accessed on November 1. Retrived from https://www.moleg.go.kr/

[5] Chou SC, Boldy DP, and Lee AH. (2002). Resident satisfaction and its components in residential aged care. The Gerontologist, Vol. 42, No. 2.

[6] National health insurance. Assessed on November 1. Retrived https://www.longtermcare.or.kr/npbs/indexr.jsp

[7] National Health Insurance. (2021). 2021 Long-Term Care Rating Committee Briefing Session, Gwangju Jeolla Jeju Regional Headquarters.

[8] National Health Insurance. Assessed on November 1. Retrived from http://ligsystemup.kdtidc.com/ebook/2021 ebook/ebook.html

[9] Ministry of Health and Welfare. Assessed on November 1. Retrived from http://www.mohw.go.kr/react/index.jsp

[10] Woo Kuk-hee. (2006). Participation of Private Commercial Sector for Expanding Supply of Care Services for the Elderly in the UK and Implications for Korea, Research on the Elderly Welfare, 32, 223-245.

[11] Sookmyung. (2007). A Study on Long-term Care Policy for the Elderly in England, Care Welfare in Korea, 8, 7-231. 